\title{
The Cost of Care Associated with Microvascular Free Tissue Transfer by Anatomical Region: A Time-Driven Activity-Based Model
}

\author{
Jackson S. Lindell, BS ${ }^{1}$ Breanna L. Blaschke, BA ${ }^{1,2}$ Arthur J. Only, MD ${ }^{3}$ Harsh R. Parikh, MPH ${ }^{1,4}$ \\ Tiffany L. Gorman, MD ${ }^{4}$ Sandy X. Vang, BA ${ }^{1,4}$ Ashish Y. Mahajan, MD ${ }^{1}$ Brian P. Cunningham, MD 3 \\ ${ }^{1}$ Department of Orthopaedic Surgery, Regions Hospital, St. Paul, \\ Minnesota \\ ${ }^{2}$ Department of Orthopaedic Surgery, TRIA Orthopaedic Center, \\ Bloomington, Minnesota \\ ${ }^{3}$ Department of Orthopaedic Surgery, Methodist Hospital, St. Louis \\ Park, Minnesota \\ ${ }^{4}$ Department of Orthopaedic Surgery, University of Minnesota, \\ Minneapolis, Minnesota \\ Address for correspondence Brian P. Cunningham, MD, 6500 \\ Excelsior Boulevard, St. Louis Park, MN 55426 \\ (e-mail: brian.cunningham@parknicollet.com).
}

J Reconstr Microsurg Open 2021;6:e28-e34.

\author{
Abstract \\ Keywords \\ - free tissue transfer \\ (FTT) \\ - time-driven activity- \\ based cost (TDABC) \\ - indirect costs \\ - direct costs
}

Background Microvascular free tissue transfer (FTT) is a reliable method for reconstruction of complex soft tissue defects. The goal of this study was to utilize time-driven activity-based cost (TDABC) accounting to measure the total cost of care of FTT and identify modifiable cost drivers.

Methods A retrospective review was performed on patients requiring FTT at a single, level-I academic trauma center from 2013 to 2019. Patient and surgical characteristics were collected, and six prospective FTT cases were observed via TDABC to collect direct and indirect costs of care.

Results When stratified by postoperative stay at intensive care units (ICUs), the average cost of care was $\$ 21,840.22$, while cases without ICU stay averaged $\$ 6,646.61$. The most costly category was ICU stay, averaging $\$ 8,310.99$ (40.9\% of nonstratified overall cost). Indirect costs were the second most costly category, averaging $\$ 4,388.07$ (21.6\% of nonstratified overall cost). Overall, 13 of 100 reviewed cases required some form of revision free-flap, increasing cumulative costs to $\$ 7,961.34$ for cases with nonICU stay and $\$ 22,233.85$ for cases with ICU stay, averaging up to $\$ 44,074.07$ for patients who stayed in the ICU for both procedures. An increase in cumulative cost was also observed within the timeframe of the investigation, with average costs of $\$ 8,484.00$ in 2013 compared to $\$ 45,128$ for 2019 .

Conclusion Primary drivers for cost in this study were ICU stay and revision/reoperation. Better understanding the cost of FTT allows for cost reduction through the development of new protocols that drive intraoperative efficiency, reduce ICU stays, and optimize outcomes. received

December 15, 2020 accepted after revision February 15, 2021
Dol https://doi.org/ $10.1055 / \mathrm{s}-0041-1729639$ ISSN 2377-0813.

\footnotetext{
(C) 2021. The Author(s).

This is an open access article published by Thieme under the terms of the Creative Commons Attribution-NonDerivative-NonCommercial-License, permitting copying and reproduction so long as the original work is given appropriate credit. Contents may not be used for commercial purposes, or adapted, remixed, transformed or built upon. (https://creativecommons.org/ licenses/by-nc-nd/4.0/) Thieme Medical Publishers, Inc., 333 Seventh Avenue, 18th Floor, New York, NY 10001, USA
} 


\section{Introduction}

Microvascular free tissue transfer (FTT) is a reliable method for reconstruction of complex soft tissue defects. The overall incidence of diagnoses that require management with FTT is rare; however, extremity trauma, breast cancer reconstruction, and head and neck cancer are three of the most common scenarios to utilize FTT. ${ }^{1-4}$ Open fractures can present with significant accompanying soft tissue loss preventing primary closure. Management of soft tissue reconstruction with FTT has been the preferred treatment method. ${ }^{5}$ Head and neck reconstructions continue to be one of the most common applications of FTT, which, while technically demanding is still considered the gold standard for these situations when compared with alternative treatment options. ${ }^{6,7}$

Treatment with FTT is accompanied by potential complications including the occasional need for urgent exploration, revision procedures, longer operative times, high-resource utilization, and failure rates reported up to $7.7 \% .^{7-12}$ The cost of FTT procedures is not well documented in literature. To our knowledge, past literature has been isolated to an analysis of factors related to viability and success rates of FTT, ${ }^{13-16}$ while studies examining the cost effectiveness of FTT have been limited to small cohorts or highly specific patient populations. ${ }^{8,17,18}$ To date, an accurate cost analysis of FTT has not been performed.

National expenditures on health care have been steadily increasing and are projected to reach nearly $20 \%$ of the gross domestic product (GDP) by $2025 .^{19}$ In order to improve overall value in health care, there must be more transparency in cost for products and services among providers, hospital administrators, and payers. Many traditional cost accounting (TCA) methods in hospitals utilize a top-down approach, summing all direct and indirect costs and then allocating them to patients using arbitrarily determined cost-to-charge ratios (CCRs). While this approach is simple, it has considerable limitations when applied to multiple departments or health systems simultaneously, and does not provide accurate patient-level cost information. ${ }^{20}$ Time-driven activity-based costing (TDABC) was developed as a "microcosting" solution, utilizing a bottom-up approach where the cost of each service is determined by multiplying the cost of one unit of time by the amount of time utilized by the patient for each step in an episode of care. ${ }^{20,21}$ TDABC has been used in a variety of health care settings analyzing cost effectiveness ${ }^{22-24}$ including orthopaedic trauma. ${ }^{25}$ The goal of this study was to establish foundational data for the preferred management of significant soft-tissue reconstruction by performing TDABC to provide detailed insight into the total cost of care of FTT.

\section{Methods}

Following institutional review board (IRB) approval, a retrospective cohort study was collected, comprised of patients treated from February 2013 to August 2019 at a single, level-I academic trauma center. Inclusion criteria were procedures requiring FTT. Cases involving concomitant procedures requiring more than 60 minutes of operating room (OR) time were excluded from the study. Study case records were assessed for attending surgeon, information regarding demographics, indication, surgical procedure and site, preoperative/operative/postoperative stay time, complications, and need for reoperation. Each patient was followed for 6 months to assess for any potential complications that may have arisen postoperatively. Surgical decision-making was at the discretion of the attending plastic surgeon, including but not limited to flap design and location, postoperative protocol including monitoring, elevation, time to split-thickness skin grafting (STSG), and revision or exploration.

A boot strapping methodology was utilized for TDABC analysis which had previously been published. ${ }^{25-27} \mathrm{~A}$ total of six prospective FTT cases were directly observed from October 2018 through July 2019. The time spent on direct patient care for a variety of personnel was recorded (-Fig. 1), ranging from preoperative care through the postoperative acute care unit (PACU). Process maps were generated for the preoperative area, $\mathrm{OR}$, and postoperative areas to determine the amount of time spent and the personnel associated with each activity. Operative time, PACU time, and secondary recovery time were all variable within our process maps. These times were extracted from the electronic medical record for each patient. The time for each additional process was measured by research personnel observing in the respective areas. Personnel cost per unit time was derived from salary, an $80 \%$ practical capacity assumption, cost of benefits, cost of information technology (IT), and cost of human resource (HR) services to support each employee. The only exception to this was the cost associated with the plastic surgeon, which was determined based on work relative value units for common procedure terminology. Supply cost was calculated from the negotiated price for each item at our institution identified in the charge master.

\section{Results}

A total of 100 patients met inclusion criteria and underwent FTT for extensive soft tissue loss, with a mean age of $44.6 \pm 18.5$ years old at time of surgery. Twenty-eight of the 100 cases requiring FTT were isolated to the foot and ankle, 50 to the remainder of the lower extremities, 10 to the head and neck, and 12 to upper extremities ( - Table 1 ). A total of 29 of the FTT cases required only free-flap management, while three necessitated additional full-thickness skin grafting (FTSG). The remaining 68 retrospective cases required free flap with additional STSG, with an average overall cost of $\$ 20,326.05$ for all cases reviewed. The most common mechanism of injury (MOI) was motor vehicle crash with 37 documented cases, while degloving and electrocution were the least common with one case each ( - Table 1). During the course of our retrospective review, a trend developed with an increased percentage of intensive care unit (ICU) admissions each year (-Fig. 2). Over the same period of time the number of cases requiring revision were identified (-Fig. 2). Seventy-eight of the 100 retrospective cases required an ICU stay postoperatively while the remaining 22 (22\%) didn't require postoperative ICU management. When stratified by ICU postoperative stay, the average 


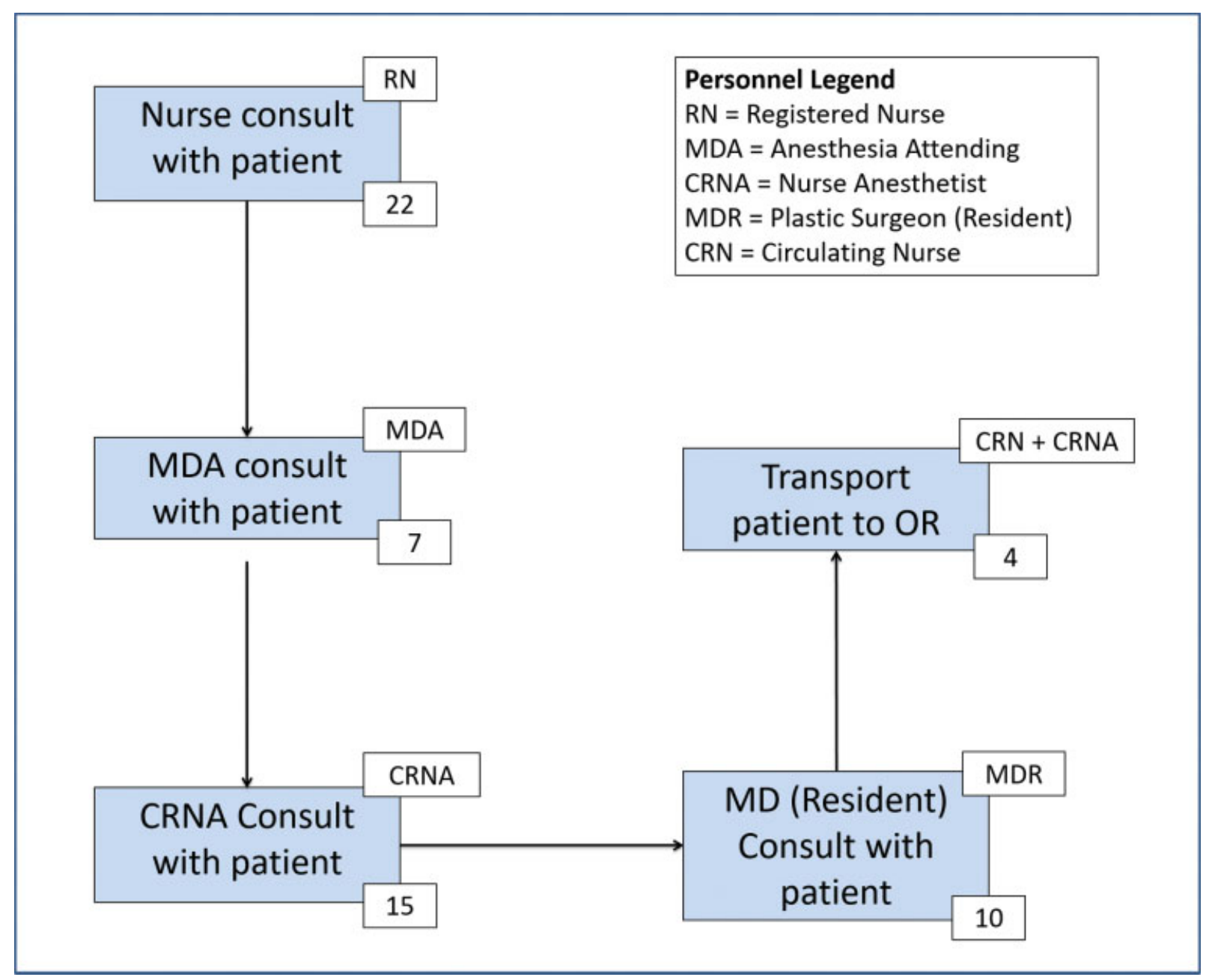

Fig. 1 Preoperative workflow map with personnel involved and their average time contributions. OR, operating room.

cost of care was $\$ 21,840.22$, while the cases without ICU stay had an average cost of $\$ 6,646.61$. The most costly category for the reviewed FTT, on average, was the ICU stay at $\$ 8,310.99$ (40.9\% of nonstratified overall cost; - Fig. 3 ). Indirect costs were the second most costly category, averaging $\$ 4,388.07$ (21.6\% of nonstratified overall cost; - Fig. 3 ).

Thirteen of the 100 reviewed cases (13\%) required some form of revision free-flap (-Table 1). Of the patients who were sent to the ICU, 10 of 78 (12.8\%) needed a revision. Of the patients who were not sent to the ICU, 3 of 22 needed a revision (13.6\%). When compared, this was not statistically significant $(p=1.00)$. However, while the rate is $0.8 \%$ higher, a power analysis suggests that you would need nearly 82,000 patients to find a statistically significant difference. The cumulative costs increased by $\$ 7,961.34$ for cases with non-ICU stay and by $\$ 22,233.85$ for cases with ICU stay, with the average totaling up to $\$ 44,074.07$ for patients who stayed in the ICU for both procedures. The ICU stay remained the most costly portion of care for FTT cases requiring revision, at a total cost of $\$ 14,803.49$ (35.8\%), while the secondary procedure cost was

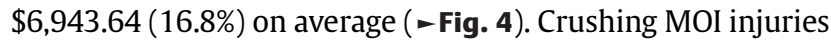
had the highest cumulative cost with an average cost of $\$ 26,639.97$. Upper extremity injuries were the most costly anatomical location, averaging $\$ 22,776.21$, and free flaps were the most costly of the three surgical procedures with an average cost of $\$ 22,689.98$ ( - Fig. 5). An increase in cumulative cost for FTT procedures was also observed within the timeframe of this investigation, with the average cost of $\$ 8,484.00$ in 2013 compared to $\$ 45,128$ for 2019 ( - Fig. 6), reflecting an increase in ICU stays, from $40 \%$ of cases in 2013 to $84.6 \%$ of cases in 2019.

\section{Discussion}

The purpose of this study was to accurately measure the cost of care for FTT using a TDABC analysis. The analysis of 100 FTT procedures performed at a high volume microsurgical level-I trauma center demonstrated an average cost of care of $\$ 20,326.05$. When stratified by non-ICU versus ICU postoperative stay, the overall costs averaged $\$ 6,646.61$ and $\$ 21,840.22$, respectively. This cost increased up to $\$ 44,074.07$ in ICU cases requiring free-flap revisions. Interestingly, indirect costs were the second most costly facet of care for FTT cases, averaging $\$ 4,388.07$ (21.6\%), and increasing to a total of $\$ 6,425.08$ for cases requiring revision. This large allocation of indirect costs is attributable to the high resource utilization of FTT including extended operative times, utilization of specialized equipment, and the occasional management of complications. It is apparent 
Table 1 Population characteristics for study sample between 2013 and $2019(n=100)$

\begin{tabular}{|c|c|}
\hline & $n$ \\
\hline Gender & $\begin{array}{l}\text { Female: } 24 \\
\text { Male: } 76\end{array}$ \\
\hline $\begin{array}{l}\text { Age }(y) \\
\text { Mean } \pm \text { SD [95\% Cl] }\end{array}$ & $44.6 \pm 18.5[40.9,48.3]$ \\
\hline Injury location & $\begin{array}{l}\text { Foot/ankle: } 28 \\
\text { ankle: } 11 \\
\text { Foot/heel: } 10 \\
\text { Foot: } 7 \\
\text { Head/neck: } 10 \\
\text { Scalp/head: } 6 \\
\text { Jaw: } 4 \\
\text { Hip/knee/leg: } 50 \\
\text { Hip: } 4 \\
\text { Upper leg: } 6 \\
\text { Knee: } 5 \\
\text { Lower leg: } 35 \\
\text { Shoulder/arm/elbow: } 12 \\
\text { Shoulder: } 1 \\
\text { Forearm: } 5 \\
\text { Elbow: } 3 \\
\text { Hand: } 3\end{array}$ \\
\hline Surgical procedure & $\begin{array}{l}\text { Free-flap: } 29 \\
\text { Free-flap w/FTSG: } 3 \\
\text { Free-flap w/STSG: } 68\end{array}$ \\
\hline $\begin{array}{l}\text { Mechanism } \\
\text { of injury }\end{array}$ & $\begin{array}{l}\text { Motor vehicle crash: } 37 \\
\text { Fall: } 23 \\
\text { Motor vehicle crash-pedestrian: } 8 \\
\text { Fire: } 8 \\
\text { Gunshot wound: } 7 \\
\text { Crush: } 7 \\
\text { Blast: } 4 \\
\text { Lawn mower accident: } 4 \\
\text { Degloving: } 1 \\
\text { Electrocution: } 1\end{array}$ \\
\hline Intensive care unit & 78 \\
\hline $\begin{array}{l}\text { Flaps requiring } \\
\text { revision }\end{array}$ & $\begin{array}{l}13 \\
\text { Hip/knee/leg: } 6 \\
\text { Ankle: } 5 \\
\text { Forearm: } 1 \\
\text { Scalp/head: } 1\end{array}$ \\
\hline
\end{tabular}

Abbreviations: $\mathrm{Cl}$, confidence interval; FTSG, full-thickness skin grafting; SD, standard deviation; STSG, split-thickness skin grafting.

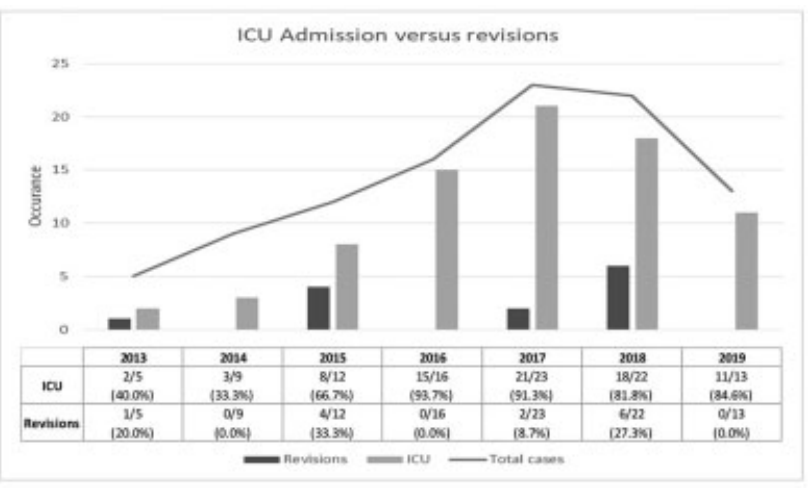

Fig. 2 Trend of the ICU admissions from 2013 to 2019 for free-tissue transfer (FTT) cases along with number of the same cases requiring revision procedures. ICU, intensive care unit.

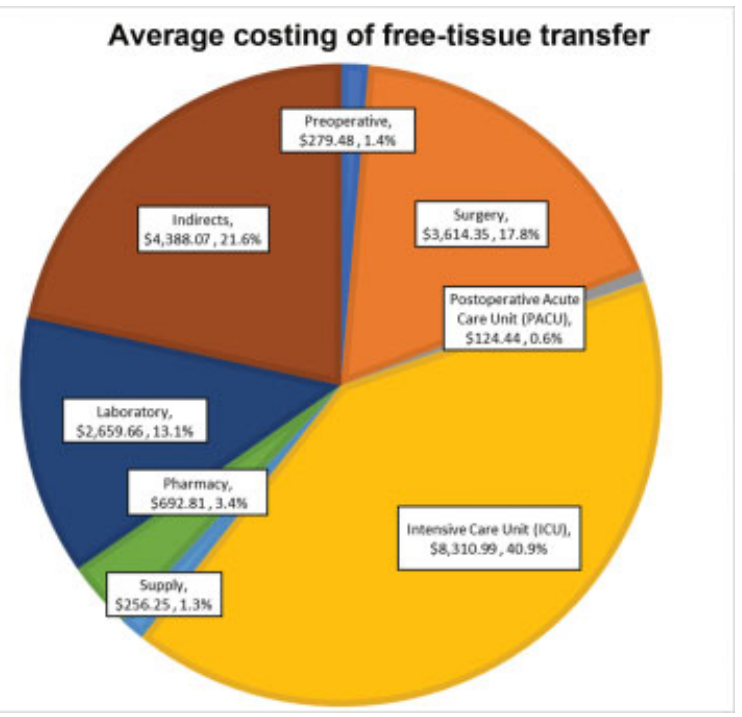

Fig. 3 A breakdown of the costing dynamics for the average primary freetissue transfer (FTT) case evaluated in this study. The following will further stratify which costs are accumulated to each category. Supply: the costs associated with the physical materials utilized during the patient's surgical encounter, preoperative through postoperative acute care unit (PACU), within the health care facility. Pharmacy: the costs associated to all pharmacological agents assigned to the patient during their stay within the health care facility. This cost is allocated from the medication purchase price of the institution, not the institutional charge. Laboratory: the costs associated to all radiological and laboratory tests performed during the patients' surgical encounter and subsequent hospital stay. Indirects: the indirect costing allocation for the patient's surgical encounter, see page 3 for further details of indirect costing. Preoperative: the personnel costs attributed to a patient's stay in the surgical preoperative ward prior to their surgical procedure. Surgery: the personnel costs attributed to those involved during the patient's individual surgical procedure. Derived via time-driven activity-based costing (TDABC). PACU: the personnel costs attributed to a patient's stay in the PACU following their surgical procedure. Intensive care unit (ICU): the costs attributed to patient's stay within the ICU, directly allocating costs for all personnel and room supplies.

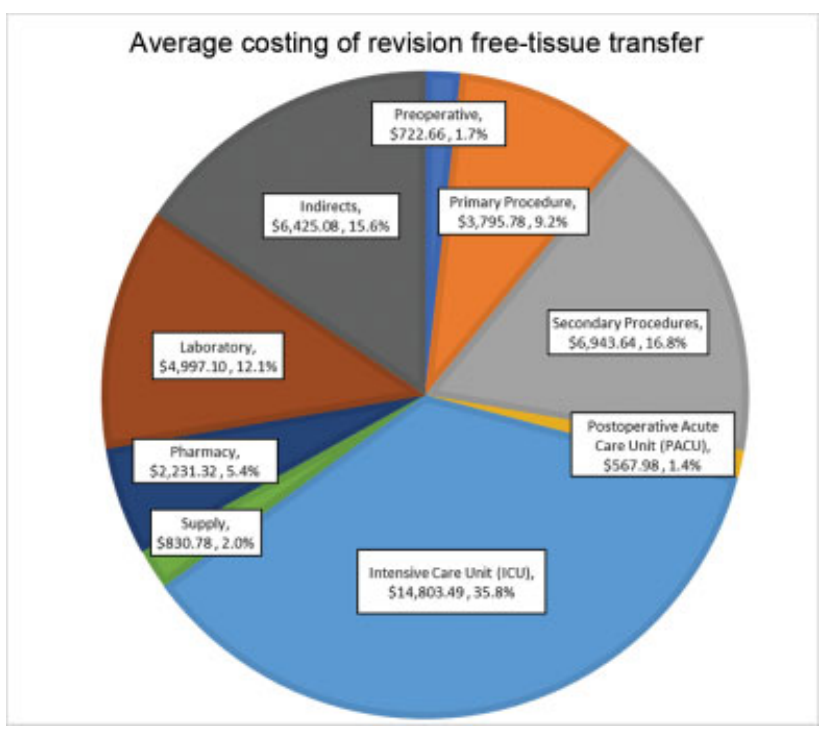

Fig. 4 A breakdown of the costing dynamics for the average revision free-tissue transfer (FTT) case evaluated in this study. The following will further stratify any additional categories that were not discussed in - Fig. 3. Secondary procedures: any subsequent procedures following the initial FTT procedure. These procedures include: irrigation and debridement (I\&Ds) and revision FTT procedures. 
e32 Microvascular Free Tissue Transfer by Anatomical Region Lindell et al.

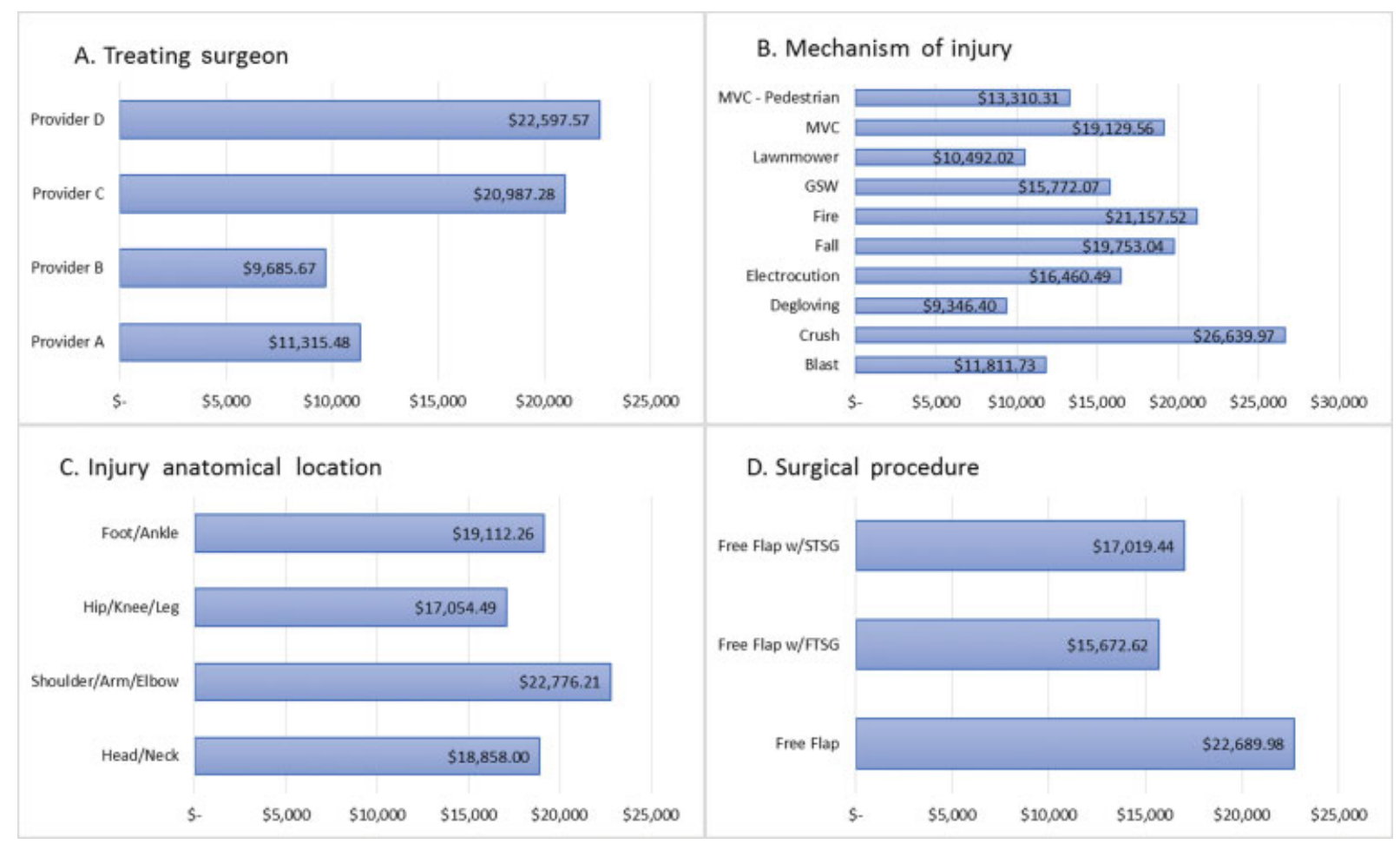

Fig. 5 Free-tissue transfer (FTT) costing averages stratified by: (A) treating surgeon, (B) mechanism of injury, (C) injury anatomical location, and (D) surgical procedure type.

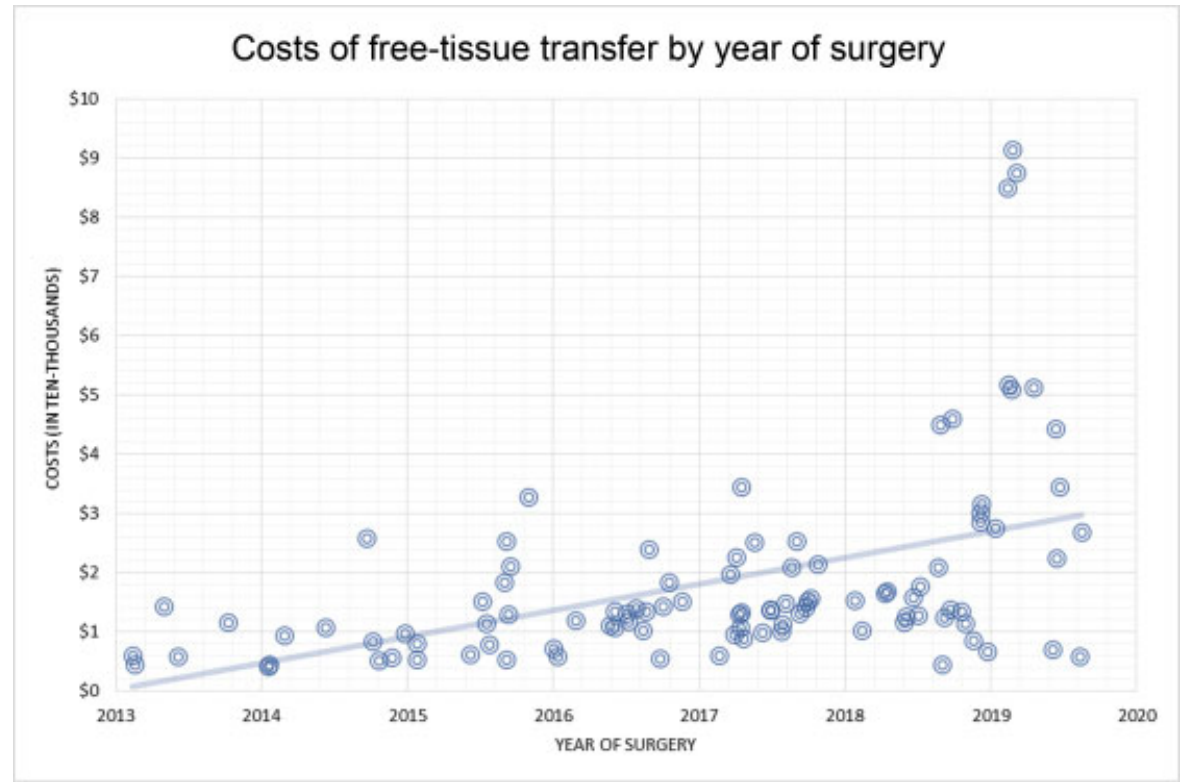

Fig. 6 Cumulative costs for free-tissue transfer (FTT) procedures performed between 2013 and 2019. An overall increasing trend is observed within the timeframe of this investigation.

from review of the medical records, from 2013 to 2019, there was an increased tendency toward ICU admission and monitoring thus increasing the total cost of care (-Fig. 2). Although our sample size is not of adequate power to establish statistical significance, comparing the number of necessary revisions each year with the number of ICU admissions appears to indicate ICU admission does not protect against the need for surgical revisions.
Accurate cost analysis of FTT has not been documented in literature, with the majority of studies dedicated to investigating viability and success factors related to FTT, ${ }^{13-16}$ or isolated to highly specific patient populaitons..$^{8,17,18}$ The use of TDABC allowed our study to analyze the cost of care which has historically been estimated by a proxy such as hospital charges or reimbursement. ${ }^{21}$ In addition, TDABC allows for the capture of direct and indirect costs of care associated 
with each perioperative case. Direct costs are those that are directly attributable to patient care such as the attending surgeon professional fees. Indirect costs are generalized expenses that are not explicitly attributed to a patient's care but are necessary to support the direct costs, for example, the cost of heating or cooling each OR to the surgeon's desired temperature. The TCA method doesn't differentiate between direct and indirect costing, but rather sums and distributes the hospital's overall incurred cost. ${ }^{20}$ This inability to distinguish between direct and indirect costs can cause huge variation in costing between systems and therefore wasn't the most effective approach to match our goal of creating a generalizable model of FTT cost.

Value in health care has been defined as patient outcome achieved divided by the total cost of care. ${ }^{28}$ The TDABC method utilized in this study allowed the authors to investigate the cost of care involved in FTT, a necessary element of its value which had previously been poorly documented. TDABC methodology also provides the opportunity to more appropriately investigate the complex breakdown of direct and indirect costs utilized by patients, and the exclusion of extraneous indirect costs not utilized by patients gives a clearer and more generalizable total cost of the procedure. In the present study, a consistent increase in total cost was observed between 2013 and 2019, with average FTT costs of $\$ 8,484$ and $\$ 45,128$ in 2013 and 2019, respectively (-Fig. 6). This costing increase, given the time period, necessitates the exploration of alternative and more cost-conscientious treatment options in order to improve the value of FTT.

Interestingly, researchers in various fields who perform FTT have gradually come to similar conclusions over the past decade, notably in breast ${ }^{5}$ and head and neck reconstruction. The costs and outcomes of alternative treatments have been compared to FTT, such as implant versus pedicled flap versus free flap breast reconstruction, ${ }^{1-4,6}$ or pedicled pectoralis versus free flap reconstruction of the mandible. ${ }^{7}$ In our study, ICU stays generated the majority of costs. In both academic and nonacademic practices, clinical pathways which reduce or eliminate ICU stays are becoming more common. ${ }^{8,9}$ Shorter hospital stays are becoming more common. ${ }^{8,13}$ These changes reflect economic pressures which affect us all, but some studies also show potentially higher risk associated with an ICU stay such as sepsis.

Our research includes two-fold utilities. First, we suggest that another method of measuring cost can be applied to procedures such as FTT and TDABC. Secondly, our data support the general shift away from expensive care if quality of care can be maintained. Recent head and neck literature, in particular, contains several suggestions to improve outcomes while reducing cost such as preoperative risk analysis, ${ }^{17}$ patient optimization, alternative reconstructions, ${ }^{22}$ and fast-track postoperative protocols. ${ }^{14}$ Head and neck cancer patients are among those with the highest risk for complications, given their tendency to cachexia, tobacco/alcohol use, and preoperative or postoperative radiation therapy exposure. Multiple authors in this field report that outcomes are equivalent if not better when ICU stays are avoided. ${ }^{15,16,18,20}$ If it is possible to simplify care and reduce costs for these patients without compromising quality, it should be possible to do so for relatively healthy orthopaedic trauma patients undergoing limb salvage which involves free tissue transplantation.

\section{Strengths and Limitations}

The present study had a number of strengths and weaknesses. To our knowledge, this was the first study to utilize TDABC analysis to investigate the costs of care for FTT broadly across indications and anatomical regions. Additionally, the compiled prospective data facilitated the creation of a timedriven costing algorithm that may be applied to a variety of different sites in various institutional settings. A weakness of this study is that data were limited to a single center. As mentioned prior, there is a growing trend among providers to avoid ICU admission as a routine protocol in the postoperative management of patients undergoing an FTT. Our findings only reported the practices of a single institution with an apparent preference for ICU admission following FTT. The findings in our study may not be representative of institutions that have already adopted a more efficient practice of avoiding ICU admission as a precautionary measure. Since the goal was to provide a thorough and extensive investigation into a variety of cases requiring FTT, additional institutional data could provide a more substantial and thorough inquiry. The literature has demonstrated variation in outcomes and protocols across microvascular centers ${ }^{10,11}$ which could alter the numerical values reported in our study.

\section{Conclusion}

The purpose of this study was to accurately measure the cost of care for FTT using a TDABC analysis. Our study is consistent with the established literature that ICU cost along with cases requiring revisions significantly leads to elevations in the cost of care for the treatment of conditions requiring FTT. However, the increased tendency to opt for ICU admission appears not to be associated with a reduction in incidences of revisions. The primary driver for cost in our study was patients who were being monitored in the ICU or who needed revision/reoperation. Better understanding the cost of FTT allows for institutional cost reduction through the development of new protocols that drive intraoperative efficiency, reduce ICU stays, and optimize outcomes. The power of TDABC can be leveraged to compare the cost of care for FTT across health care organizations creating a pathway forward toward value-driven care.

\section{Financial Disclosure Statement}

B.P.C. reports a grant from Integra associated with the conduct of the study; outside the submitted work, wife is CEO and founder of CODE Technology.

\section{Conflict of Interest}

B.P.C. reports a grant from Integra associated with the conduct of the study; outside the submitted work, wife is CEO and founder of CODE Technology. S.X.V. reports a grant from Integra related to the conduct of the study. 


\section{References}

1 Bakhach J, Abou Ghanem O, Bakhach D, Zgheib E. Early free flap reconstruction of blast injuries with thermal component. Ann Burns Fire Disasters 2017;30(04):303-308

2 Townley WA, Urbanska C, Dunn RLR, Khan U. Costs and codingfree-flap reconstruction in lower-limb trauma. Injury 2011;42 (04):381-384

3 Schusterman MA, Miller MJ, Reece GP, Kroll SS, Marchi M, Goepfert H. A single center's experience with 308 free flaps for repair of head and neck cancer defects. Plast Reconstr Surg 1994; 93(03):472-478, discussion 479-480

4 Wax MK, Burkey BB, Bascom D, Rosenthal EL. The role of free tissue transfer in the reconstruction of massive neglected skin cancers of the head and neck. Arch Facial Plast Surg 2003;5(06): $479-482$

5 Fischer MD, Gustilo RB, Varecka TF. The timing of flap coverage, bone-grafting, and intramedullary nailing in patients who have a fracture of the tibial shaft with extensive soft-tissue injury. J Bone Joint Surg Am 1991;73(09):1316-1322

6 Heller L, Levin LS. Lower extremity microsurgical reconstruction. Plast Reconstr Surg 2001;108(04):1029-1041, quiz 1042

7 Khouri RK, Shaw WW. Reconstruction of the lower extremity with microvascular free flaps: a 10-year experience with 304 consecutive cases. J Trauma 1989;29(08):1086-1094

8 Thornton BP, Rosenblum WJ, Pu LLQ. Reconstruction of limited soft-tissue defect with open tibial fracture in the distal third of the leg: a cost and outcome study. Ann Plast Surg 2005;54(03): 276-280

9 Byrd HS, Spicer TE, Cierney G III. Management of open tibial fractures. Plast Reconstr Surg 1985;76(05):719-730

10 Kwok AC, Agarwal JP. An analysis of free flap failure using the ACS NSQIP database. Does flap site and flap type matter? Microsurgery 2017;37(06):531-538

11 Fischer JP, Wink JD, Nelson JA, et al. A retrospective review of outcomes and flap selection in free tissue transfers for complex lower extremity reconstruction. J Reconstr Microsurg 2013;29 (06):407-416

12 Shasti M, Jauregui JJ, Malik A, Slobogean G, Eglseder WA, Pensy RA. Magnitude of soft-tissue defect as a predictor of free flap failures: does size matter? J Orthop Trauma 2017;31(12): e412-e417

13 Koul AR, Patil RK, Nahar S. Unfavourable results in free tissue transfer. Indian J Plast Surg 2013;46(02):247-255

14 Bui DT, Cordeiro PG, Hu QY, Disa JJ, Pusic A, Mehrara BJ. Free flap reexploration: indications, treatment, and outcomes in 1193 free flaps. Plast Reconstr Surg 2007;119(07):2092-2100
15 Pohlenz P, Blessmann M, Blake F, Li L, Schmelzle R, Heiland M. Outcome and complications of 540 microvascular free flaps: the Hamburg experience. Clin Oral Investig 2007;11(01):89-92

16 Nakatsuka T, Harii K, Asato H, et al. Analytic review of 2372 free flap transfers for head and neck reconstruction following cancer resection. J Reconstr Microsurg 2003;19(06):363-368, discussion 369

17 Fischer JP, Sieber B, Nelson JA, et al. Comprehensive outcome and cost analysis of free tissue transfer for breast reconstruction: an experience with 1303 flaps. Plast Reconstr Surg 2013;131(02): 195-203

18 Shirley R, Fazekas J, McNally M, Ramsden A. Costs and renumeration of osteomyelitis treatment involving free flaps: implications of return to theatre. J Bone Jt Infect 2018;3(01):15-19

19 Keehan SP, Stone DA, Poisal JA, et al. National health expenditure projections, 2016-25: Price increases, aging push sector to 20 percent of economy. Health Aff (Millwood) 2017;36(03):553-563

20 Kaplan RS, Anderson SR. Time-driven activity-based costing. Harv Bus Rev 2004;82(11):131-138, 150

21 Parikh HR, O'Hara N, Levy JF, Cunningham BP. Value Denominator: The Fundamentals of Costing for Orthopaedic Surgeons. J Orthop Trauma 2019;33(S, suppl 7):S56-S61

22 Donovan CJ, Hopkins M, Kimmel BM, Koberna S, Montie CA. How Cleveland Clinic used TDABC to improve value. Healthc Financ Manage 2014;68(06):84-88

23 Akhavan S, Ward L, Bozic KJ. Time-driven activity-based costing more accurately reflects costs in arthroplasty surgery. Clin Orthop Relat Res 2016;474(01):8-15

24 Martin JA, Mayhew CR, Morris AJ, Bader AM, Tsai MH, Urman RD. Using time-driven activity-based costing as a key component of the value platform: a pilot analysis of colonoscopy, aortic valve replacement and carpal tunnel release procedures. J Clin Med Res 2018;10(04):314-320

25 McCreary DL, White M, Vang S, Plowman B, Cunningham BP. Time-driven activity-based costing in fracture care: is this a more accurate way to prepare for alternative payment models? J Orthop Trauma 2018;32(07):344-348

26 McCreary DL, Dugarte AJ, Vang S, et al. Patient-level value analysis: an innovative approach to optimize care delivery. J Orthop Trauma 2019;33(S, suppl 7):S49-S52

27 White M, Parikh HR, Wise KL, Vang S, Ward CM, Cunningham B. Cost savings of carpal tunnel release performed in-clinic compared to an ambulatory surgery center: time-driven activitybased costing. J Hand Surg Am 2018;43(09):S9

28 Porter ME. What is value in health care? N Engl J Med 2010;363 (26):2477-2481 